\title{
STRATEGI DAN KEBIJAKAN MANAJEMEN DALAM PENGAWASAN PRODUK PERSEDIAAN DI PT. XYZ INDONESIA
}

\author{
Oleh: \\ Rimsa Rusmiland ${ }^{1}$ \\ Dian Jingga Permana ${ }^{2}$ \\ Program Studi Teknik Industri \\ Fakultas Teknik dan Ilmu Komputer \\ Universitas Indraprasta PGRI \\ Email: \\ Rrfj60@gmail.com ${ }^{1}$ \\ dianjpermana@gmail.com²
}

\begin{abstract}
ABSTRAK
PT. XYZ Indonesia memiliki lebih dari 6.000 produk item, dan hampir $70 \%$ produk diimpor dari banyak cabang XYZ CO di berbagai negara di dunia. Saat ini mengalami masalah dengan meningkatnya persediaan produk. Penyebab utamanya diduga salahnya strategi bisnis dan pemasaran yang diterapkan. Tujuan penelitian berfokus kepada: 1) Mencari faktor penyebab terjadinya peningkatan inventaris. 2). Menentukan strategi agar persediaan yang ideal agar mencegah terjadinya Non-Working Inventory (NWI) di masa depan? Penelitian ini menggunakan metode analisis SWOT yang kemudian dihubungkan dengan Analisis C\&E atau diagram tulang ikan dan kemudian menggunakan Strategi Bisnis Porter Generic serta BCG Matrix (Boston Consulting Group Matrix). Kesimpulan: 1) Ada 3 faktor yang menyebabkan peningkatan persediaan produk dalam 2 tahun terakhir. 2). langkah-langkah yang diperlukan PT. XYZ Indonesia dalam memperbaik masalah terdiri atas: Memperbaiki strategi pemasaran yang kurang fokus dan tidak tepat, Membangun Kemitraan serta perluasan jaringan dengan melibatkan departemen terkait lainnya seperti departemen Legal, Supply Chain dan Pembinaan diperlukan karena program pembinaan akan memiliki interaksi dua arah dan topik yang spesifik serta fokus pada penyelesaian masalah.
\end{abstract}

Kata kunci: SWOT, Analisis C\&E, Strategi Bisnis Porter Generic, Matrix BCG

\begin{abstract}
PT. XYZ Indonesia has more than 6,000 product items, and almost $70 \%$ of products are imported from many XYZ CO branches in various countries in the world. Currently experiencing problems with increasing product inventory. The main reason is allegedly the wrong business and marketing strategies applied. The research objectives focus on: 1). Look for factors causing an increase in inventory. 2). Determine a strategy so that the ideal inventory in order to prevent the Non-Working Inventory (NWI) in the future? This research method uses a SWOT analysis which is then linked to $C \& E$ analysis or fishbone diagrams and
\end{abstract}


then uses the Porter Generic Business Strategy and the BCG Matrix (Boston Consulting Group Matrix). Conclusion: 1). There are 3 factors that have caused an increase in product inventory in the last 2 years. 2). steps needed by PT. XYZ Indonesia in fixing the problem consists of Improving marketing strategies that are less focused and inappropriate, Building Partnerships and network expansion by involving other relevant departments such as Legal, Supply Chain and Coaching is needed because the coaching program will have two-way interactions and specific topics and focus on solving problems.

Keywords: SWOT, C\&E Analysis, Porter Generic Business Strategy, BCG Matrix

\section{A. PENDAHULUAN}

Memulai bisnis produk Abrasif dari lima orang pengusaha yang memulai usaha penambangan deposit mineral untuk abrasive roda gerinda, XYZ CO didirikan pada tahun 1902 di kota Lake Superior Two Harbors, Minnesota. Tetapi deposit terbukti tidak banyak nilainya, dan selanjutnya, dibentuklah perusahaan dengan nama Minnesota Mining and Manufacturing Co yang dengan cepat pindah ke kota Duluth untuk khusus pada produk amplas. Lima pengusaha Minnesota utara yang rajin ulet dengan beragam keahlian ini menjadi pendiri awal XYZ CO, XYZ CO terlibat dalam produksi beberapa rekaman audio digital pertama pada akhir 1970-an untuk melihat merilis komersial produk ketika mesin prototipe dibawa ke studio Sound 80 di Minneapolis.

Setelah menarik pengalaman dari perekam prototipe itu, pada tahun 1979, perusahaan ini kemudian memperkenalkan sistem perekaman audio digital yang tersedia secara komersial yang disebut "Sistem Penguasaan Audio Digital XYZ CO", yang terdiri dari perekam audio tape digital 32-track dan sebuah pendamping 4-lacak perekam digital. XYZ CO kemudian merancang dan memproduksi beberapa model perekam audio digital lain yang tersedia secara komersial yang digunakan sepanjang awal hingga pertengahan 1980-an. Pada 1980, perusahaan itu memperkenalkan Post-it notes

Saat ini, dengan penjualan \$30 miliar, XYZ CO mempekerjakan 88.000 orang di seluruh dunia dan menghasilkan lebih dari 55.000 produk, termasuk: perekat, abrasive, laminasi, perlindungan kebakaran pasif, produk gigi, bahan elektronik, produk medis, produk perawatan mobil (film matahari, cat, pelindung cat, shampo mobil, perawatan untuk perlindungan karat eksterior, interior dan rangka bawah), sirkuit elektronik, dan film optik. XYZ CO berjalan di lebih dari 65 negara termasuk 29 perusahaan internasional dengan operasi manufaktur dan 35 perusahaan dengan laboratorium. Produk-produk tersedia untuk dibeli melalui distributor dan pengecer di lebih dari 196 negara, dan online langsung dari perusahaan

XYZ CO telah beroperasi di Indonesia semenjak tahun 1975 dengan nama PT XYZ Indonesia. Seperti banyak anak perusahaan XYZ CO lainnya di seluruh dunia, selalu membawa berbagai produk dan layanan jasa ke pasar lokal. Fasilitas awal produksi berlokasi di Cibinong tetapi kemudian dipindahkan di TambunBekasi ke fasilitas manufaktur baru pada tahun 1980. Kantor Penjualan \& Administrasi berlokasi di Kawasan Pusat Bisnis Jakarta hingga. Ada juga kantor 
Penjualan cabang yang berlokasi di Surabaya. Pada tahun 2013, PT. XYZ Indonesia memiliki lebih dari 6.000 produk item, dan hampir $70 \%$ produk diimpor dari banyak cabang XYZ CO di berbagai negara di dunia.

Dalam 4 tahun terakhir, PT. XYZ Indonesia mengalami masalah dengan meningkatnya persediaan produk. Penyebab utamanya diduga salahnya strategi bisnis dan pemasaran yang diterapkan. Hal ini bisa dari rantai pasokan juga. Dengan produk barang yang luas dan banyak, dan juga kesalahan dalam strategi telah menciptakan peningkatan persediaan produk seperti yang ditunjukkan pada tahun 2018 (Gambar 1). Target Non-Working Inventory (NWI) atau persediaan barang yang tidak bergerak. Hal ini seharusnya dikurangi secara bertahap hingga akhir tahun, tetapi ternyata menunjukkan bahwa NWI selalu memiliki tren meningkat secara signifikan hingga akhir bulan. PT. XYZ Indonesia memiliki aturan untuk mengelola inventaris. Status lambat adalah jika produk menjadi lebih besar dan pergantian stok lebih dari 2 bulan. Untuk kelebihan produk yang dimaksud adalah produk yang memiliki pesanan lebih tinggi dari perkiraan. Biasanya inventori yang dimiliki hampir satu sampai dua kali penjualan bulanan. Namun dalam 3 tahun terakhir jumlahnya hampir 3 hingga 4 kali. Stok mati adalah produk yang dimiliki yang belum pindah selama enam bulanatau lebih dari gudang.

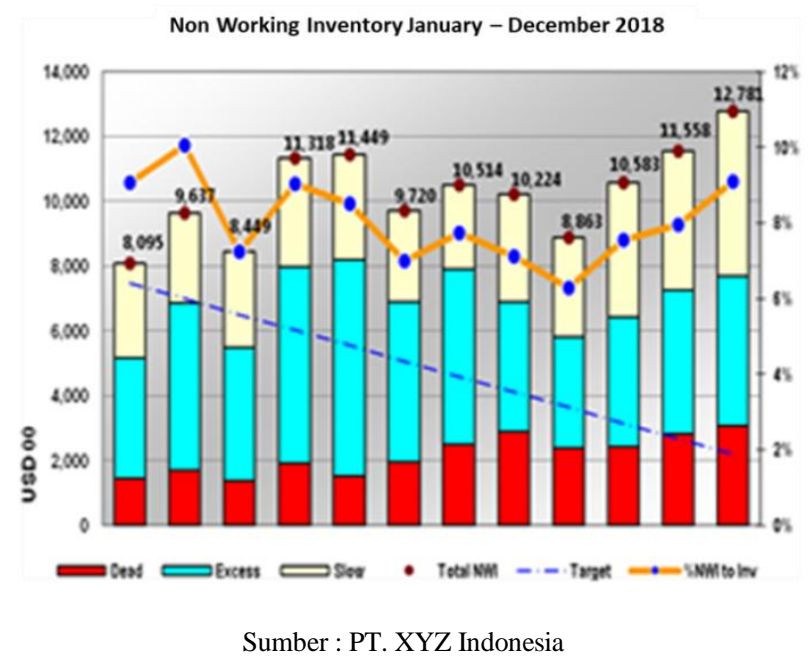

Gambar1.

Non Working Inventory Januar1- Desember 2018

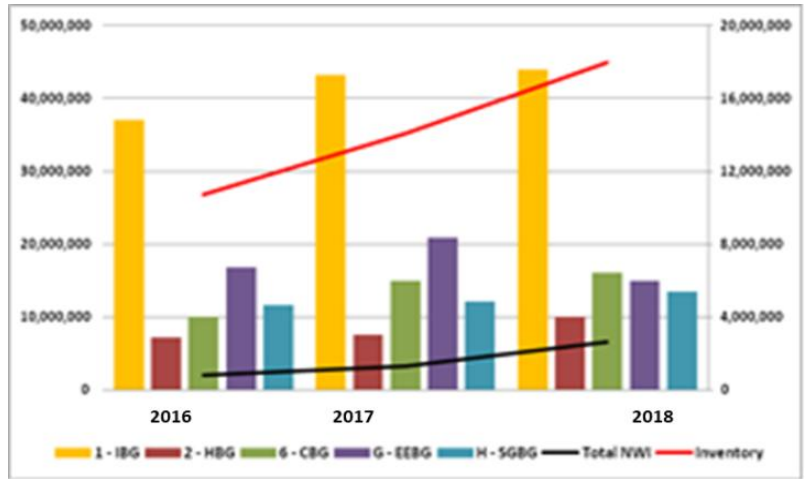




\section{Sumber :PT. XYZ Indonesia \\ Gambar 2. \\ Sales vsInventory vs NW I (USD) 2016 - 2018}

Berdasarkan Gambar 2 diatas, maka situasi pasar pada tahun depan (2019) akan terlihat seperti tidak dapat diprediksi karena pemilihan umum Presiden dan Legislatif di Indonesia. Tentu, itu akan berdampak pada masalah ekonomi, politikdan pada akhirnya juga akan berdampak pada semua bisnis, manufaktur, perdagangan infrastruktur, termasuk dalam PT. XYZ Indonesia. Oleh karena itu, penting dan perlu membuat strategi dan kebijakan agar menciptakan pertumbuhan penjualan dari pelanggan sehingga bisnis akan terus tumbuh dan berkembang, dan permintaan menjadi meningkat maka diharapkan persediaan atau inventori akan turun secara bertahap dan biaya juga mengikutinya. Setiap perusahaan harus dapat melakukan kegiata yang berbeda dari para kompetitornya, karena rantai nilai yang berbeda dapat dapat membangun keunggulan kompetitif secara berkelanjutan.(Porter \& Gibbs, 2001). Disisi lain dengan membangun keunggulan dengan menilai apa yang dilakukan pesaing dan berusaha untuk melakukannya dengan lebih baik dapat digunakan dalam mempertahankan diri di pasar.(Kim W. Chan; Mauborgne Renée, 2010). Berdasarkan latar belakang diatas maka tujuan penelitian berfokus kepada:1.) mencari faktor apa saja yang menciptakan tren peningkatan inventaris? dan2.) Menentukan strategi agar persediaan atau inventori menjadi di tingkat yang ideal agarmencegah terjadinya Non-Working Inventory $(N W I)$ atau inventori yang berlebihan agar terjadi di masa depan?

\section{B. METODOLOGI PENELITIAN}

Pemecahan permasalahan dalam penelitian ini menggunakan metode kualitatif melaluialat analisis SWOT yang kemudian dikombinasikan dengan Analisis $\mathrm{C} \& \mathrm{E}$ atau diagram tulang ikan untuk memperjelas akar utama masalah yang terjadi. Ada 8 elemen utama yang menjadi prioritas utama untuk diselesaikan dan 6 elemen pada prioritas kedua, kemudian dihubungkan dengan analisis SWOT. Diagram tulang ikan digunakan dalam menganalisis permasalahan di tingkat individu, kelompok, maupun organisasi (Asmoko, 2013). SWOT seperti banyak pendekatan tinjauan umum yang digunakan dalam strategi, bertujuan untuk memecahkan masalah strategis dengan meninjau perusahaan sebagai keseluruhan, menutupi keragaman perusahaan dengan solusi generik (Hill \& Westbrook, 1997). Agar dapat memperjelas tentang kebijakan harga, mengatur waktu tunggu dan juga menguasai pasar, perlu menganalisis semua produk dengan beberapa metode untuk lebih memperjelas posisi produk dan keberlanjutan di pasar. Dua pendekatan untuk menjawab masalah ini yang menggunakan Strategi Bisnis Porter Generic, dan yang kedua adalah BCG Matrix (Boston Consulting Group Matrix). Ada tiga strategi generik yang merupakan titik awal yang baik untuk pemikiran strategis: kepemimpinan biaya keseluruhan, diferensiasi, dan fokus (Porter, 1980). Matriks Boston Consulting Group (BCG) digunakan dalam menentukan alternatif-alternatif strategi yang paling ideal bagi perusahaan, sehingga membantu perusahaan dalam meraih keunggulan bersaing (Guntara, Yogaswara, \& Aurachman, 2017). 


\section{HASIL DAN PEMBAHASAN}

\section{Menggali Isu-isu Bisnis}

Ada 2 aspek masalah dari inventaris di PT. XYZ Indonesia. Masalah pertama berasal dari internal dan yang kedua dari eksternal. Internal berasal dari kelompok 1, urutan aliran proses (flow order process). Kelompok 2, kebijakan (policy), strategi pemasaran (marketing strategy), eksekusi (execution). Kelompok 3, struktur organisasi (organization structure), sumber daya manusia (HR), yang terdiri dari kompetensi kerja (job competency), kapabilitas (capability), pengembangan manusia dan perilaku atau sikap (Human development and behavior/attitude). Faktor eksternal berasal dari pesaing (competitors), faktor ekonomi(economic), regulasi (regulation), permintaan pasar (demand market), semua faktor terkait atau berdampak pada masalah inventori dapat ditemukan pada gambar 3 dibawah ini.

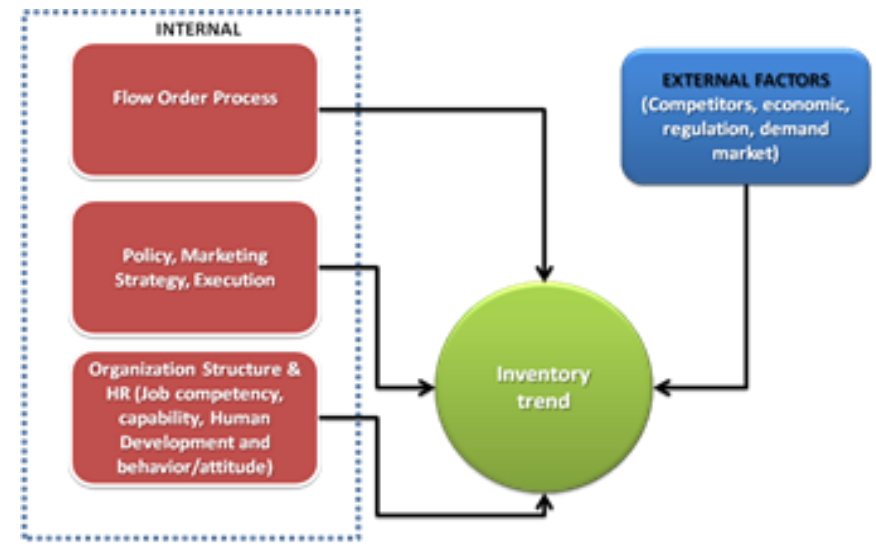

Gambar 3.

\section{Hubungan dan MasalahUtama Persediaan di PT. XYZ Indonesia}

PT. XYZ Indonesia memiliki dua jenis untuk menjual produk mereka kepada pelanggan. Yang pertama adalah bisnis ke bisnis (B2B) yang merupakan produk pasokan PT. XYZ Indonesia ke industri, dan yang lainnya adalah bisnis ke pelanggan (B2C) atau pengguna akhir. Hampir semua jenis produk akan dikirimkan dan didistribusikan oleh distributor. Hanya sedikit item penjualan produk yang langsung ke pelanggan atau pengguna akhir. PT.XYZ Indonesia bermitra dengan distributor untuk pemenuhan stok. Biasanya, pasokan untuk memenuhi stok minimal satu bulan. Karena itu jika PT. XYZ Indonesia menjual produk untuk distributor di bulan ini, berarti hal itu untuk penjualan bulan depan di distributor. Jadi secara umum, inilah yang terjadi dalam situasi normal. Umumnya, bagian marketing akan memberikan proyeksi penjualan selama 1 tahun dan membagi berdasarkan bulan untuk perincian kepada distributor.

Kemudian mereka akan menyesuaikan ramalan bergulir tiga bulan (rolling forecast) ke depan sehingga membuat persediaan yang baik dan menghindari kesalahan pesanan, marketing dan distributor bertemu untuk membahas tentang permintaan reguler pasokan untuk menentukan jumlah permintaan mereka dan 
juga membahas bagaimana memasok produk pada waktu yang tepat bagi pelanggan. Kedua belah pihak memiliki alasan dan tawar-menawar untuk permintaan jumlah pasokan jika ada permintaan yang tidak terduga baik permintaan pelanggan dikurangi atau sebaliknya ditambah. Pertemuan ini akan memiliki suatu kesimpulan. Bagian marketing akan memberikan resume ini atau merevisi forecast ke bagian inventory planningdan bagiancustomer service, kemudian inventory planningakan membuat perencanaan untuk produksi atau pesanan berdasarkan perkiraan, dan persediaan produk atau bahan baku di gudang, dan juga batas waktu suplai.

\section{Analisa SWOT}

\begin{tabular}{|c|c|}
\hline SWOT Analysis & Potential Impact (Negative factor) \\
\hline \multicolumn{2}{|l|}{ STRENGTHS } \\
\hline $\begin{array}{l}\text { Strong research and development } \\
\text { capability }\end{array}$ & $\begin{array}{c}\text { Imitated product by competitor without } \mathrm{R} \\
\text { and } \mathrm{D}\end{array}$ \\
\hline Diversified business portfolio & Low control, slow moving \\
\hline \multicolumn{2}{|l|}{ Strong financial performances } \\
\hline \multicolumn{2}{|l|}{$\begin{array}{l}\text { Strong return on average assets and } \\
\text { investments }\end{array}$} \\
\hline \multicolumn{2}{|l|}{ WEAKNESSES } \\
\hline Poor inventory management & Discrepancy, dead stock, inventory cost high \\
\hline $\begin{array}{c}\text { Increasing cost of raw material, } \\
\text { import cost and lead time }\end{array}$ & $\begin{array}{c}\text { Competitiveness opportunity high with lower } \\
\text { price }\end{array}$ \\
\hline $\begin{array}{c}\text { Poor marketing plan for numerous } \\
\text { products }\end{array}$ & $\begin{array}{c}\text { Wrongly analyze of demand, Slow moving, } \\
\text { dead stock }\end{array}$ \\
\hline Human resource development & Poor skill demotivated and lack of teamwork. \\
\hline \multicolumn{2}{|l|}{ OPPORTUNITIES } \\
\hline \multicolumn{2}{|l|}{$\begin{array}{c}\begin{array}{c}\text { Growing demand for LCDs or electronic } \\
\text { industry }\end{array} \\
\end{array}$} \\
\hline $\begin{array}{l}\text { Economic growth, especially the } \\
\text { growth of infrastructure }\end{array}$ & lose the opportunity to win tenders \\
\hline \multicolumn{2}{|l|}{ Global expansion } \\
\hline \multicolumn{2}{|l|}{ THREATS } \\
\hline Growth in private labels & $\begin{array}{l}\text { Competitiveness opportunity high with lower } \\
\text { price }\end{array}$ \\
\hline Exchange rate fluctuations & Price \\
\hline Slowdown in the US and Euro zone & Price, lead time delivery \\
\hline
\end{tabular}

\section{Gambar 4. \\ Analisis SWOT}

Dalam memperjelas identifikasi penyebab masalahnya, ada 2 alat pendukung untuk melakukan analisa yang tepat. Yang pertama adalah analisa SWOT dan yang kedua adalah Cause and Effect Diagram (Fish bone Diagram). Tujuan dari analisa SWOT adalah untuk melihat secara global atau makro bagaimana bisnis PT. XYZ Indonesia. Melihat PT. XYZ Indonesia secara makro tentunya juga melihat produknya. Sehubungan dengan masalah yang dihadapi dalam tingginya persediaan produk, ditemukan faktor-faktor dalam elemen SWOT yang memiliki potensi atau dampak negatif yang menyebabkan peningkatan jumlah item persediaan. Berdasarkan analisis SWOT yang terdapt pada Gambar 4, PT. XYZ Indonesia memiliki 9 poin (Potential Impact) yang berpotensi berdampak negatif yang akan membuat daya saing produk menjadi lemah, sebagai akibatdari akumulasi produk di gudang.

\section{Analisis Sebab dan Akibat (Diagram Tulang Ikan)}

Tujuan diagram Sebab dan Akibat atau diagram tulang ikan adalah untuk mengenalkan hubungan antara efek dalam situasi tertentu dan semua penyebab yang mungkin, kemudian akhirnya menemukan sumber/solusi masalah. Sebab- 
dan-efek membantu untuk memahami mengapa sesuatu terjadi atau apa hasil dari suatu peristiwa. Efek adalah apa yang terjadi dan penyebab yang berkontribusi mengapa itu terjadi.Dalam hal ini, untuk menentukan mengapa persediaan (inventory) produk memiliki tren peningkatan yang signifikan dapat dijelaskan pada Gambar 5.

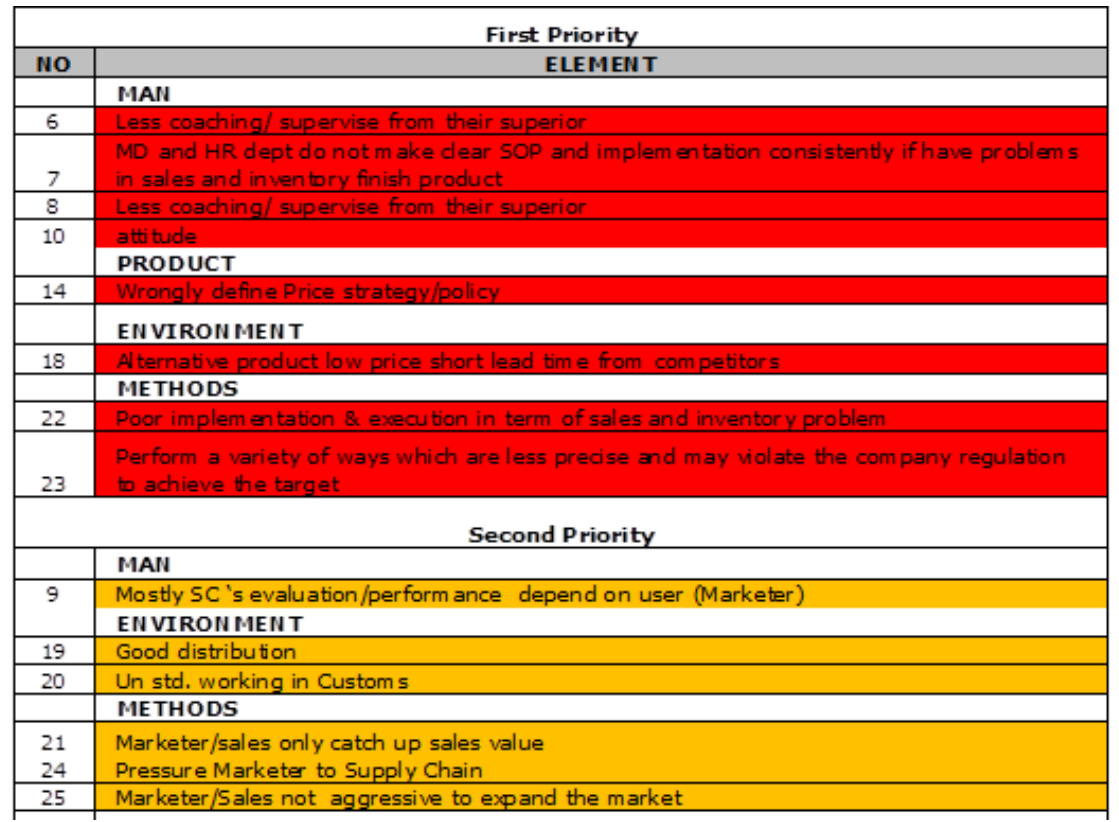

Gambar 5. Analisis C\&E

Berdasarkan gambar diatas maka dapat terlihat bahwa:

1. 8 elemen yang terhubung ke lebih dari 2 menyebabkan masalah berasal, menjadikan prioritas pertama.

2. 6 elemen yang terhubung ke 1-2 menyebabkan masalah dan ada di prioritas kedua.

3. 4 elemen dalam prioritas pertama dan 1 elemen dari prioritas kedua berasal dari faktor Man.

4. Prioritas 1 elemen berasal dari faktor Produk

5. Prioritas pertama 1 elemen dan prioritas kedua 2 elemen berasal dari faktor Lingkungan

6. Prioritas 2 elemen 2 dan prioritas kedua 3 elemen berasal dari faktor lingkunganPelatihan untuk bagian marketing dan rantai pasokan.

\section{Analisi Strategi Bisnis Porter Generic dan Matrix BCG}

Menentukan dan memilih untuk produk dan mampu dan bersaing di pasar maka dibutukan Ada 2 alat bantu analisis, yaituStrategi Bisnis Porter Generic dan Matrix BCG.Berdasarkan Tabel diatas maka maksud dari daftar ini adalah untuk mengurangi produk yang penjualannya rendah dan persaingan yang tinggi. Yang kedua adalah memberikan perhatian dan fokus yang lebih kuat pada produk yang memang memiliki potensi dan pangsa pasar yang kuat. Dan yang ketiga adalah 
meningkatkan fokus produk yang memiliki potensi dan keunggulan dalam hal biaya dan diferensiasi produk yang tinggi, sesuai dengan strategi generik BCG dan Porter juga.

Tabel 1.

Agenda Rencana dan ImplementasiPT. XYZ Indonesia

\begin{tabular}{|c|c|c|c|c|c|c|c|}
\hline & \multirow{2}{*}{$\begin{array}{l}\text { Potential } \\
\text { Impact } \\
\text { (Negative } \\
\text { factor) }\end{array}$} & \multicolumn{2}{|c|}{$\begin{array}{c}C \& E \text { Analysis (Fish Bone } \\
\text { Diagram) }\end{array}$} & \multirow[t]{2}{*}{$\begin{array}{l}\text { Conclus } \\
\text { ion }\end{array}$} & \multicolumn{3}{|c|}{ Recommendation } \\
\hline & & Element & $\begin{array}{c}\text { Component } \\
\text { /department } \\
\text { responsibilitie } \\
\text { s }\end{array}$ & & \begin{tabular}{|c|} 
Porter \\
Gene \\
ric \\
Strat \\
egy
\end{tabular} & $\begin{array}{l}\text { BCG } \\
\text { Matr } \\
\quad \text { ix }\end{array}$ & $\begin{array}{l}\text { Coach } \\
\text { ing }\end{array}$ \\
\hline \multicolumn{8}{|l|}{$\begin{array}{l}\text { STRENGTH } \\
S\end{array}$} \\
\hline \multirow{3}{*}{$\begin{array}{l}\text { Strong } \\
\text { research and } \\
\text { development } \\
\text { capability }\end{array}$} & \multirow{3}{*}{$\begin{array}{l}\text { Imitated } \\
\text { product by } \\
\text { the } \\
\text { competitor } \\
\text { with low } \\
\text { price, short } \\
\text { lead time, } \\
\text { wide } \\
\text { distribution }\end{array}$} & $\begin{array}{l}\text { Wrong } \\
\text { define Price } \\
\text { strategy/pol } \\
\text { icy }\end{array}$ & $\begin{array}{l}\text { Marketer, } \\
\text { MD, } \\
\text { Policy/regula } \\
\text { tion, }\end{array}$ & \multirow[b]{2}{*}{$\begin{array}{c}\text { More } \\
\text { focus in } \\
\text { Marketi } \\
\text { ng } \\
\text { Strategy } \\
(4 P)\end{array}$} & $\square$ & $\square$ & $\square$ \\
\hline & & $\begin{array}{l}\text { Poor } \\
\text { implementat } \\
\text { ion \& } \\
\text { execution in } \\
\text { term of } \\
\text { sales and } \\
\text { inventory } \\
\text { problem } \\
\end{array}$ & $\begin{array}{l}\text { Marketer, } \\
\text { SC, MD, } \\
\text { Support Dept }\end{array}$ & & $\square$ & $\square$ & $\square$ \\
\hline & & $\begin{array}{l}\text { Good } \\
\text { distribution }\end{array}$ & $\begin{array}{l}\text { Marketer, } \\
\text { DC }\end{array}$ & $\begin{array}{c}\text { Partners } \\
\text { hip \& } \\
\text { Network }\end{array}$ & & & $\square$ \\
\hline \multirow[t]{3}{*}{$\begin{array}{c}\text { Diversified } \\
\text { business } \\
\text { portfolio }\end{array}$} & \multirow[t]{3}{*}{$\begin{array}{l}\text { Low } \\
\text { control, } \\
\text { slow- } \\
\text { moving }\end{array}$} & $\begin{array}{l}\text { MD and HR } \\
\text { dept do not } \\
\text { make clear } \\
\text { SOP and } \\
\text { implementat } \\
\text { ion } \\
\text { consistently } \\
\text { if have } \\
\text { problems in } \\
\text { sales and } \\
\text { inventory } \\
\text { finish } \\
\text { product }\end{array}$ & $\begin{array}{l}\text { MD, } \\
\text { Policy/Regul } \\
\text { ation, } \\
\text { Support } \\
\text { Dept. }\end{array}$ & \multirow[t]{2}{*}{$\begin{array}{l}\text { Executio } \\
n \text { and } \\
\text { Leaders } \\
\text { hip }\end{array}$} & & & $\square$ \\
\hline & & $\begin{array}{l}\text { Less } \\
\text { coaching/ } \\
\text { supervise } \\
\text { from their } \\
\text { superior }\end{array}$ & $\begin{array}{l}\text { Marketer, } \\
\text { SC, MD, } \\
\text { Support Dept }\end{array}$ & & & & $\square$ \\
\hline & & $\begin{array}{l}\text { Good } \\
\text { distribution }\end{array}$ & $\begin{array}{l}\text { Marketer, } \\
\text { DC }\end{array}$ & $\begin{array}{c}\text { Partners } \\
\text { hip \& } \\
\text { Network }\end{array}$ & & & $\square$ \\
\hline $\begin{array}{l}\text { WEAKNESS } \\
\text { ES }\end{array}$ & & & & & & & \\
\hline
\end{tabular}




\begin{tabular}{|c|c|c|c|c|c|c|c|}
\hline \multirow{3}{*}{$\begin{array}{c}\text { Poor } \\
\text { inventory } \\
\text { management }\end{array}$} & \multirow{3}{*}{$\begin{array}{c}\text { The } \\
\text { discrepanc } \\
y, \\
\text { deadstock, } \\
\text { inventory } \\
\text { cost high }\end{array}$} & $\begin{array}{l}\text { Less } \\
\text { coaching/ } \\
\text { supervise } \\
\text { from their } \\
\text { superior }\end{array}$ & $\begin{array}{l}\text { Marketer, } \\
\text { SC, MD, } \\
\text { Support Dept }\end{array}$ & \multirow[b]{2}{*}{$\begin{array}{c}\text { Executio } \\
n \text { and } \\
\text { Leaders } \\
\text { hip }\end{array}$} & & & $\square$ \\
\hline & & $\begin{array}{l}\text { MD and HR } \\
\text { dept do not } \\
\text { make clear } \\
\text { SOP and } \\
\text { implementat } \\
\text { ion } \\
\text { consistently } \\
\text { if have } \\
\text { problems in } \\
\text { sales and } \\
\text { inventory } \\
\text { finish } \\
\text { product }\end{array}$ & $\begin{array}{l}\text { MD, } \\
\text { Policy/Regul } \\
\text { ation, } \\
\text { Support } \\
\text { Dept. }\end{array}$ & & & & $\square$ \\
\hline & & $\begin{array}{l}\text { Good } \\
\text { distribution }\end{array}$ & $\begin{array}{l}\text { Marketer, } \\
\text { DC }\end{array}$ & $\begin{array}{c}\text { Partners } \\
\text { hip \& } \\
\text { Network }\end{array}$ & & & $\square$ \\
\hline $\begin{array}{l}\text { The } \\
\text { increasing } \\
\text { cost of raw } \\
\text { material, } \\
\text { import cost } \\
\text { and lead time }\end{array}$ & $\begin{array}{l}\text { Competitiv } \\
\text { eness } \\
\text { opportunity } \\
\text { high with } \\
\text { the lower } \\
\text { price }\end{array}$ & $\begin{array}{l}\text { Alternative } \\
\text { product low } \\
\text { price short } \\
\text { lead time } \\
\text { from } \\
\text { competitors }\end{array}$ & $\begin{array}{l}\text { Marketer, } \\
\text { SC, MD, } \\
\text { Support Dept }\end{array}$ & \multirow{3}{*}{$\begin{array}{c}\text { More } \\
\text { focus in } \\
\text { Marketi } \\
\quad n g \\
\text { Strategy } \\
(4 P)\end{array}$} & $\square$ & $\square$ & $\square$ \\
\hline \multirow{2}{*}{$\begin{array}{l}\text { Poor } \\
\text { marketing } \\
\text { plan for } \\
\text { numerous } \\
\text { products }\end{array}$} & \multirow{2}{*}{$\begin{array}{l}\text { Wrongly } \\
\text { analyze of } \\
\text { demand, } \\
\text { Slow- } \\
\text { moving, } \\
\text { deadstock }\end{array}$} & $\begin{array}{l}\text { Wrong } \\
\text { define Price } \\
\text { strategy/pol } \\
\text { icy }\end{array}$ & \multirow[t]{4}{*}{$\begin{array}{l}\text { Marketer, } \\
\text { MD, } \\
\text { Policy/regula } \\
\text { tion, }\end{array}$} & & $\square$ & $\square$ & $\square$ \\
\hline & & $\begin{array}{l}\text { Alternative } \\
\text { product low } \\
\text { price short } \\
\text { lead time } \\
\text { from } \\
\text { competitors }\end{array}$ & & & $\square$ & $\square$ & $\square$ \\
\hline \multirow{3}{*}{$\begin{array}{c}\text { Human } \\
\text { resource } \\
\text { development }\end{array}$} & \multirow{3}{*}{$\begin{array}{c}\text { Poor skill } \\
\text { and } \\
\text { demotivate } \\
d \text {, lack of } \\
\text { teamwork }\end{array}$} & $\begin{array}{l}\text { Less } \\
\text { coaching/ } \\
\text { supervise } \\
\text { from their } \\
\text { superior }\end{array}$ & & \multirow[b]{2}{*}{$\begin{array}{l}\text { Executio } \\
n \text { and } \\
\text { Leaders } \\
\quad \text { hip }\end{array}$} & & & $\square$ \\
\hline & & $\begin{array}{l}\text { Perform a } \\
\text { variety of } \\
\text { ways which } \\
\text { are less } \\
\text { precise and } \\
\text { may violate } \\
\text { the } \\
\text { company } \\
\text { regulation } \\
\text { to achieve } \\
\text { the target }\end{array}$ & & & & & $\square$ \\
\hline & & attitude & $\begin{array}{l}\text { MD, } \\
\text { Policy/Regul }\end{array}$ & $\begin{array}{c}\text { More } \\
\text { focus in }\end{array}$ & & & $\square$ \\
\hline
\end{tabular}




\begin{tabular}{|c|c|c|c|c|c|c|c|}
\hline & & & $\begin{array}{l}\text { ation, } \\
\text { Support } \\
\text { Dept. }\end{array}$ & $\begin{array}{l}\text { Marketi } \\
\text { ng } \\
\text { Strategy } \\
(4 P)\end{array}$ & & & \\
\hline \multicolumn{8}{|l|}{$\begin{array}{l}\text { OPPORTUNI } \\
\text { TIES }\end{array}$} \\
\hline \multirow{2}{*}{$\begin{array}{l}\text { Economic } \\
\text { growth, } \\
\text { especially the } \\
\text { growth of } \\
\text { infrastructure }\end{array}$} & \multirow{2}{*}{$\begin{array}{l}\text { lose the } \\
\text { opportunity } \\
\text { to win } \\
\text { tenders }\end{array}$} & $\begin{array}{l}\text { Less } \\
\text { coaching/ } \\
\text { supervise } \\
\text { from their } \\
\text { superior }\end{array}$ & \multirow{2}{*}{$\begin{array}{c}\text { Marketer, } \\
\text { SC, MD, } \\
\text { Support Dept }\end{array}$} & $\begin{array}{l}\text { Executio } \\
n \text { and } \\
\text { Leaders } \\
\text { hip }\end{array}$ & & & $\square$ \\
\hline & & $\begin{array}{l}\text { Alternative } \\
\text { product low } \\
\text { price short } \\
\text { lead time } \\
\text { from } \\
\text { competitors }\end{array}$ & & \multirow{5}{*}{$\begin{array}{c}\text { More } \\
\text { focus in } \\
\text { Marketi } \\
\quad n g \\
\text { Strategy } \\
(4 P)\end{array}$} & $\square$ & $\square$ & $\square$ \\
\hline THREATS & & & & & & & \\
\hline $\begin{array}{c}\text { Growth in } \\
\text { private labels }\end{array}$ & $\begin{array}{c}\text { Competitiv } \\
\text { eness } \\
\text { opportunity } \\
\text { high with } \\
\text { the lower } \\
\text { price }\end{array}$ & $\begin{array}{l}\text { Wrong } \\
\text { define Price } \\
\text { strategy/pol } \\
\text { icy }\end{array}$ & \multirow{5}{*}{$\begin{array}{c}\text { Marketer, } \\
\text { SC, MD, } \\
\text { Support Dept }\end{array}$} & & $\square$ & $\square$ & $\square$ \\
\hline \multirow{3}{*}{$\begin{array}{c}\text { Exchange } \\
\text { rate } \\
\text { fluctuations }\end{array}$} & \multirow{3}{*}{ Price } & $\begin{array}{l}\text { Wrong } \\
\text { define Price } \\
\text { strategy/pol } \\
\text { icy }\end{array}$ & & & $\square$ & $\square$ & $\square$ \\
\hline & & $\begin{array}{l}\text { Alternative } \\
\text { product low } \\
\text { price short } \\
\text { lead time } \\
\text { from } \\
\text { competitors }\end{array}$ & & & $\square$ & $\square$ & $\square$ \\
\hline & & $\begin{array}{l}\text { Less } \\
\text { coaching/ } \\
\text { supervise } \\
\text { from their } \\
\text { superior }\end{array}$ & & $\begin{array}{l}\text { Executio } \\
n \text { and } \\
\text { Leaders } \\
\quad \text { hip }\end{array}$ & & & $\square$ \\
\hline \multirow{2}{*}{$\begin{array}{c}\text { The } \\
\text { slowdown in } \\
\text { the US and } \\
\text { Eurozone }\end{array}$} & \multirow[t]{2}{*}{$\begin{array}{c}\text { Price, lead } \\
\text { time } \\
\text { delivery }\end{array}$} & $\begin{array}{l}\text { Alternative } \\
\text { product low } \\
\text { price short } \\
\text { lead time } \\
\text { from } \\
\text { competitors }\end{array}$ & & $\begin{array}{c}\text { More } \\
\text { focus in } \\
\text { Marketi } \\
\quad n g \\
\text { Strategy } \\
(4 P)\end{array}$ & $\square$ & $\square$ & $\square$ \\
\hline & & $\begin{array}{l}\text { Pressure } \\
\text { Marketer to } \\
\text { Supply } \\
\text { Chain }\end{array}$ & $\begin{array}{l}\text { Marketer, } \\
\text { MD, } \\
\text { Policy/regula } \\
\text { tion, }\end{array}$ & $\begin{array}{l}\text { Executio } \\
n \text { and } \\
\text { Leaders } \\
\quad \text { hip }\end{array}$ & & & $\square$ \\
\hline
\end{tabular}

\section{KESIMPULAN}


Dari perspektif SWOT, ada beberapa poin yang memiliki hubungan dengan analisis $\mathrm{C} \& \mathrm{E}$ atau diagram tulang ikan. Koneksi ini untuk memperkuat faktorfaktor yang menyebabkan tingginya persediaan produk. SWOT memiliki 9 elemen yang dapat berdampak negatif pada perusahaan, dan ada kompatibilitas dan koneksi dengan elemen analisis C\&E. maka dapat disimpulkan bahwa:

1. Ada 3 faktor yang menyebabkan peningkatan persediaan produk dalam 2 tahun terakhir terdiri atas :

a. Strategi pemasaran yang kurang fokus dan tidak tepat

b. Kemitraan dan jejaring (networking)

c. Eksekusi dan kepemimpinan (Excecution and leadership)

Untuk memperbaiki 3 faktor ini, perlu dilakukan perbaikan perencanaan yang ada pada elemen 4M (lihat gambar 5). Dibutuhkan beberapa departemen atau personel yang dapat membawa perubahan signifikan untuk menjalankan perbaikan dengan cepat dan sesuai dengan waktu yang telah ditargetkan.

2. Langkah-langkah yang diperlukan PT. XYZ Indonesiadalam memperbaik masalah peningkatan persediaan produkagar persediaan atau inventori menjadi di tingkat yang ideal terdiri atas:

a. Memperbaiki strategi pemasaran yang kurang fokus dan tidak tepat, Perlu ada pilihan semua produk yang akan dijual. Untuk pemilihan ini diperlukan alat yang akan dengan cepat membuat kriteria yang jelas untuk produk mana yang akan dijual dan produk mana yang tidak akan dijual lagi atau berhenti. Ada dua alat, yaitu dengan analisis Porter Strategy dan BCG Matrix.

b. Membangun Kemitraan dan Jejaring, untuk mempertahankan pertumbuhan penjualan perlu memperluas area distribusi untuk mencapai produk ke area yang lebih luas. Dan untuk mencapai itu, perusahaan harus mulai memperluas jaringan dan hubungan untuk menjalin kemitraan yang memiliki visi dan misi dan akan saling menguntungkan. Perluasan jaringan ini juga harus melibatkan departemen terkait lainnya seperti departemen Legal, Supply Chain, sehingga tidak ada celah atau kelemahan yang dapat merugikan kedua belah pihak.

c. Eksekusi dan Kepemimpinan, salah satu faktor terpenting dari masalah yang muncul adalah faktor manusia. Dalam hal ini adalah kepemimpinan dan berani mengeksekusi sesuatu keputusan penting yang telah disepakati, atau disetujui. Hampir semua divisi dalam departemen yang berhubungan dengan masalah persediaan memiliki kepemimpinan yang kurang kuat. Para pemimpin atau manager memberikan arahan dan bimbingan yang kurang memadai sehingga tim bekerja kurang cepat dan akurat. Salah satu elemen lain adalah pembinaan, yang bisa menjawab ini. Pembinaan diperlukan karena program pembinaan akan memiliki interaksi dua arah dan topik yang 
spesifik serta fokus pada penyelesaian masalah. Jika ada kesenjangan antara target dan kenyataan, maka tugas pemimpin harus memberikan arahan dan solusi dari masalah yang dihadapi.Pembinaan (Coaching) juga dapat menghadirkan motivator ahli, teman atau karyawan yang telah terbukti berhasil dalam pekerjaan mereka dan memiliki masalahnya mungkin sama dengan yang dialami saat ini, atau bahkan seseorang yang sukses dalam karirnya, yang berasal dari perusahaan lain.

\section{DAFTAR PUSTAKA}

Asmoko, H. (2013). Teknik Ilustrasi Masalah - Fishbone Diagram. Badan Pendidikan Dan Pelatihan Keuangan Departemen Keuangan, 1-8.

Guntara, S. R., Yogaswara, B., \& Aurachman, R. (2017). Strategi Transformasi PT Generation Indonesia Menuju Pendekatan Matriks Boston Consulting Group. proceedings of Engineering, 4(3), 4436-4444.

Hill, T., \& Westbrook, R. (1997). SWOT Analysis: It's Time for a Product Recall. Long Range Planning, 30(1), 46-52.

Kim W. Chan; Mauborgne Renée. (2010). Blue Ocean Strategy: From Theory to Practice. California Management Review, Bind 47, Haefte 3, 101(1-2), 105121.

Porter, M. E. (1980). e. Competitive Strategy: Techniques for Analyzing Industries and Competitors. New York: The Free Press.

Porter, M. E., \& Gibbs, M. illustrations. (2001). Strategy and the Internet. 